\title{
Self-expandable metal stents for obstructing colonic and extracolonic cancer: European Society of Gastrointestinal Endoscopy (ESGE) Clinical Guideline

Jeanin E. van Hooft ${ }^{1}$, Emo E. van Halsema ${ }^{1}$, Geoffroy Vanbiervliet ${ }^{2}$, Regina G. H. Beets-Tan ${ }^{3}$, John M. DeWitt ${ }^{4}$, Fergal Donnellan ${ }^{5}$, Jean-Marc Dumonceau ${ }^{6}$, Robert G. T. Glynne-Jones ${ }^{7}$, Cesare Hassan ${ }^{8}$, Javier Jiménez-Perez ${ }^{9}$, Søren Meisner ${ }^{10}$, V. Raman Muthusamy ${ }^{11}$, Michael C. Parker ${ }^{12}$, Jean-Marc Regimbeau ${ }^{13}$, Charles Sabbagh ${ }^{13}$, Jayesh Sagar ${ }^{14}$, Pieter J. Tanis ${ }^{15}$, Jo Vandervoort ${ }^{16}$, George J. Webster ${ }^{17}$, Gianpiero Manes ${ }^{18}$, Marc A. Barthet ${ }^{19}$, Alessandro Repici ${ }^{20}$

submitted 19. August 2014 accepted after revision 25. August 2014

\section{Bibliography}

Dol http://dx.doi.org/

10.1055/s-0034-1390700

Published online: 17.10.2014

Endoscopy 2014; 46: 990-1002

(c) Georg Thieme Verlag KG

Stuttgart · New York

ISSN 0013-726X

\section{Corresponding author}

Jeanin E. van Hooft, MD PhD

Department of

Gastroenterology and

Hepatology, C2-116

Academic Medical Center

Meibergdreef 9

1105 AZ, Amsterdam

The Netherlands

Fax: +31206917033

j.e.vanhooft@amc.uva.nl

This Guideline is an official statement of the European Society of Gastrointestinal Endoscopy (ESGE). This Guideline was also reviewed and endorsed by the Governing Board of the American Society for Gastrointestinal Endoscopy (ASGE). The Grading of Recommendations Assessment, Development, and Evaluation (GRADE) system was adopted to define the strength of recommendations and the quality of evidence.

\section{Main recommendations}

The following recommendations should only be applied after a thorough diagnostic evaluation including a contrast-enhanced computed tomography (CT) scan.

1 Prophylactic colonic stent placement is not recommended. Colonic stenting should be reserved for patients with clinical symptoms and imaging evidence of malignant large-bowel obstruction, without signs of perforation (strong recommendation, low quality evidence).

2 Colonic self-expandable metal stent (SEMS) placement as a bridge to elective surgery is not recommended as a standard treatment of symptomatic left-sided malignant colonic obstruction (strong recommendation, high quality evidence).

\begin{tabular}{ll}
\multicolumn{2}{l}{ Abbreviations } \\
ASA & American Society of Anesthesiologists \\
ASGE & $\begin{array}{l}\text { American Society for Gastrointestinal } \\
\text { Endoscopy } \\
\text { computed tomography }\end{array}$ \\
CT & $\begin{array}{l}\text { computed tomography colonoscopy } \\
\text { CTC }\end{array}$ \\
ESGE & $\begin{array}{l}\text { European Society of Gastrointestinal } \\
\text { Endoscopy }\end{array}$ \\
ICU & $\begin{array}{l}\text { intensive care unit } \\
\text { OR }\end{array}$ \\
odds ratio \\
RET & $\begin{array}{l}\text { randomized controlled trial } \\
\text { self-expandable metal stents }\end{array}$
\end{tabular}

3 For patients with potentially curable but obstructing left-sided colonic cancer, stent placement may be considered as an alternative to emergency surgery in those who have an increased risk of postoperative mortality, i.e. American Society of Anesthesiologists (ASA) Physical Status $\geq$ III and/or age $>70$ years (weak recommendation, low quality evidence).

4 SEMS placement is recommended as the preferred treatment for palliation of malignant colonic obstruction (strong recommendation, high quality evidence), except in patients treated or considered for treatment with antiangiogenic drugs (e.g. bevacizumab) (strong recommendation, low quality evidence).

\section{Introduction \\ $\nabla$}

Colorectal cancer is one of the most common cancers worldwide, particularly in the economically developed world [1]. Large-bowel obstruction caused by advanced colonic cancer occurs in $8 \%-$ $13 \%$ of colonic cancer patients [2-4]. The management of this severe clinical condition remains controversial [5]. Over the last decade many articles have been published on the subject of colonic stenting for malignant colonic obstruction, including randomized controlled trials (RCTs) and systematic reviews. However, the definitive role of self-expandable metal stents (SEMSs) in the treatment of malignant colonic obstruction has not yet been clarified. This evidence- and consensusbased clinical guideline has been developed by the European Society of Gastrointestinal Endoscopy (ESGE) and endorsed by the American Socie- 
ty for Gastrointestinal Endoscopy (ASGE) to provide practical guidance regarding the use of SEMS in the treatment of malignant colonic obstruction.

With the exception of one trial [6], all published RCTs on colonic stenting for malignant obstruction excluded rectal cancers, which were usually defined as within 8 to $10 \mathrm{~cm}$ of the anal verge, and colonic cancers proximal to the splenic flexure. Rectal stenting is often avoided because of the presumed association with complications such as pain, tenesmus, incontinence, and stent migration. Proximal colonic obstruction is generally managed with primary surgery, although there are no RCTs to support this assumption. Because of the aforementioned limitations, unless indicated otherwise the recommendations in this Guideline only apply to left-sided colon cancer arising from the rectosigmoid colon, sigmoid colon, descending colon, and splenic flexure, while excluding rectal cancers and those proximal to the splenic flexure, and other causes of colonic obstruction including extracolonic obstruction.

\section{Methods}

$\nabla$

The ESGE commissioned this Guideline (chairs C.H. and J.-M.D.) and appointed a guideline leader (J.v.H.) who invited the listed authors to participate in the project development. The key questions were prepared by the coordinating team (E.v.H. and J.v.H.) and then approved by the other members. The coordinating team formed task force subgroups, each with its own leader, and divided the key topics among these task forces (see Appendix e1, available online).

Each task force performed a systematic literature search to prepare evidence-based and well-balanced statements on their assigned key questions. The coordinating team independently performed systematic literature searches with the assistance of a librarian. The Medline, EMBASE and Trip databases were searched including at minimum the following key words: colon, cancer, malignancy or neoplasm, obstruction and stents. All articles studying the use of SEMS for malignant large-bowel obstruction were selected by title or abstract. After further exploration of the content, the article was then included and summarized in the literature tables of the key topics when it contained relevant data (see Appendix e2, $\bullet$ Tables e1-e5, available online). All selected articles were graded by the level of evidence and strength of recommendation according to the GRADE system [7]. The literature searches were updated until January 2014.

Each task force proposed statements on their assigned key questions which were discussed and voted on during the plenary meeting held in February 2014, Düsseldorf, Germany. In March 2014, a draft prepared by the coordinating team was sent to all group members. After agreement on a final version, the manuscript was submitted to Endoscopy for publication. The journal subjected the manuscript to peer review and the manuscript was amended to take into account the reviewers' comments. All authors agreed on the final revised manuscript. The final revised manuscript was then reviewed and approved by the Governing Board of ASGE. This Guideline was issued in 2014 and will be considered for review in 2019 or sooner if new and relevant evidence becomes available. Any updates to the Guideline in the interim will be noted on the ESGE website: http://www.esge.com/esgeguidelines.html.

\section{Recommendations and statements}

Evidence statements and recommendations are stated in bold italics.

\section{General considerations before stent placement \\ ( Table e1, available online) \\ $\nabla$}

Prophylactic colonic stent placement is not recommended. Colonic stenting should be reserved for patients with clinical symptoms and imaging evidence of malignant large-bowel obstruction, without signs of perforation (strong recommendation, low quality evidence). Colonic stenting is indicated only in those patients with both obstructive symptoms and radiological or endoscopic findings suspicious of malignant large-bowel obstruction. Prophylactic stenting for patients with colonic malignancy but no evidence of symptomatic obstruction is strongly discouraged because of the potential risks associated with colonic SEMS placement. The only absolute contraindication for colonic stenting is perforation. In addition, colonic stenting is less successful in patients with peritoneal carcinomatosis and tumors close to the anal verge $(<5 \mathrm{~cm})$ [8-10].

Increasing age and American Society of Anesthesiologists (ASA) classification $\geq$ III do not affect stent outcome (i.e. clinical success and complications) in several observational studies [11-16], although these are well-known risk factors for postoperative mortality after surgical treatment of large-bowel obstruction ( $\square$ Table 6) [17-19].

\section{A contrast-enhanced computed tomography (CT) scan is recommen-} ded as the primary diagnostic tool when malignant colonic obstruction is suspected (strong recommendation, low quality evidence).

When malignant colonic obstruction is suspected, contrast-enhanced CT is recommended because it can diagnose obstruction (sensitivity $96 \%$, specificity $93 \%$ ), define the level of the stenosis in $94 \%$ of cases, accurately identify the etiology in $81 \%$ of cases, and provide correct local and distal staging in the majority of patients $[5,20]$. When CT is inconclusive about the etiology of the obstructing lesion, colonoscopy may be helpful to evaluate the exact cause of the stenosis.

Examination of the remaining colon with colonoscopy or CT colonography (CTC) is recommended in patients with potentially curable obstructing colonic cancer, preferably within 3 months after alleviation of the obstruction (strong recommendation, low quality evidence).

European studies, including three that are population-based, show that synchronous colorectal tumors occur in $3 \%-4 \%$ of patients diagnosed with colorectal cancer [21 - 24]. Therefore, imaging of the remaining colon after potentially curative resection is recommended in patients with malignant colonic obstruction. Current evidence does not justify routine preoperative assessment for synchronous tumors in obstructed patients by CTC or colonoscopy through the stent. However, preoperative CTC and colonoscopy through the stent appear feasible and safe in these patients and there are presently no data to discourage their use in this population [25-28]. The role of positron emission tomography (PET)/CT in the diagnosis of synchronous lesions remains to be elucidated [29]. 
Table 6 Outcome of surgery according to age and American Society of Anesthesiologists (ASA) classification.

\begin{tabular}{|c|c|c|c|}
\hline $\begin{array}{l}\text { First author, } \\
\text { year }\end{array}$ & Study population & Results & $\begin{array}{l}\text { Study design } \\
\text { Level of evidence }\end{array}$ \\
\hline $\begin{array}{l}\text { Tekkis, } \\
2004 \text { [18] }\end{array}$ & $\begin{array}{l}\text { Patients undergoing surgery for } \\
\text { acute colorectal cancer obstruc- } \\
\text { tion }(n=1046)\end{array}$ & $\begin{array}{l}\text { Multivariate analysis of in-hospital postoperative mortality: } \\
\text { - Age< } 65 \text { years: } 5.4 \% \\
\text { - Age } 65 \text { - } 67 \text { years: } 13.1 \% \text {; OR } 2.97(95 \% \mathrm{Cl} 1.26-7.08) \\
\text { - Age } 75-84 \text { years: } 21.9 \% \text {; OR } 4.31(95 \% \mathrm{Cl} 1.83-10.05) \\
\text { - Age } \geq 85 \text { years: } 27.0 \% \text {; OR } 5.87(95 \% \mathrm{Cl} 2.27-15.14) \\
\text { - ASA I: } 2.6 \% \\
\text { - ASA II: } 7.6 \% \text {; OR } 3.32(95 \% \mathrm{Cl} 0.73-15.18) \\
\text { - ASA III: } 23.9 \% \text {; OR } 11.73(95 \% \mathrm{Cl} 2.58-53.36) \\
\text { - ASA IV - V: } 42.9 \% \text {; OR } 22.33(95 \% \mathrm{Cl} 4.58-109.68)\end{array}$ & $\begin{array}{l}\text { Nonrandomized prospec- } \\
\text { tive UK multicenter study } \\
\text { High quality evidence }\end{array}$ \\
\hline $\begin{array}{l}\text { Biondo, } \\
2004 \text { [17] }\end{array}$ & $\begin{array}{l}\text { Patients undergoing emergency } \\
\text { surgery for acute large-bowel } \\
\text { obstruction }(n=234) \\
\text { Colorectal cancer } 82.1 \% \\
\text { Extracolonic cancer } 4.7 \% \\
\text { Benign lesions } 13.2 \%\end{array}$ & $\begin{array}{l}\text { Univariate analysis of } 30 \text {-day postoperative mortality: } \\
\text { - Age } \leq 70 \text { years: } 10.7 \%(14 / 131) \\
\text { - Age }>70 \text { years: } 29.1 \%(30 / 103) ; P<0.001 \\
\text { - ASA I - II: } 8.1 \%(9 / 111) \\
\text { - ASA III - IV: } 28.5 \%(35 / 123) ; P<0.001 \\
\text { Multivariate analysis of } 30 \text {-day postoperative mortality: } \\
\text { - Age > } 70 \text { years: OR } 2.05(95 \% C I 0.92-4.60) \\
\text { - ASA III - IV: OR } 2.86(95 \% \mathrm{CI} 1.15-7.11)\end{array}$ & $\begin{array}{l}\text { No description of study } \\
\text { design, most likely retro- } \\
\text { spective } \\
\text { Moderate quality evidence }\end{array}$ \\
\hline $\begin{array}{l}\text { Tan, } \\
2010 \text { [19] }\end{array}$ & $\begin{array}{l}\text { Patients who underwent operative } \\
\text { intervention for acute obstruction } \\
\text { from colorectal malignancy } \\
(n=134)\end{array}$ & $\begin{array}{l}\text { Perioperative morbidity rate: } 77.6 \% \\
\text { Perioperative mortality rate: } 11.9 \% \\
\text { Multivariate analysis of worse outcome (grade III - V complications, } \\
\text { including death): } \\
\text { - Age > } 60 \text { years: OR } 4.67(95 \% \mathrm{Cl} 1.78-12.25) \\
\text { - ASA III - IV: OR } 8.36(95 \% \mathrm{Cl} 3.58-19.48)\end{array}$ & $\begin{array}{l}\text { Retrospective analysis } \\
\text { Low quality evidence }\end{array}$ \\
\hline
\end{tabular}

$\mathrm{Cl}$, confidence interval; OR, odds ratio.

Colonic stenting should be avoided for diverticular strictures or when diverticular disease is suspected during endoscopy and/or CT scan (strong recommendation, low quality evidence). Pathological confirmation of malignancy by endoscopic biopsy and/or brush cytology is not necessary in an urgent setting, such as before stent placement. However, pathology results may help to modify further management of the stented patient (strong recommendation, low quality evidence).

When malignancy is suspected after diagnostic studies, a small number of patients will have a benign cause of obstruction. Two RCTs comparing SEMS as a bridge to surgery versus emergency surgery in patients with left-sided malignant obstruction reported benign obstructive lesions in 4.6\% (3/65) [30] and 8.2\% (8/98) [31] of the randomized patients. These benign colonic lesions that mimic malignancy are usually due to diverticular disease. Further evidence of the difficulty of this distinction is also reflected by a systematic review showing a $2.1 \%$ prevalence of underlying adenocarcinoma of the colon in 771 patients in whom acute diverticulitis was diagnosed via CT scan [32]. Stent placement in active diverticular inflammation is associated with a risk of perforation and should therefore be avoided [33]. Furthermore, pathological confirmation of malignancy before emergency stent placement is often not feasible and is not required prior to colonic stent placement. Endoscopic biopsy and/or brush cytology for confirmation of malignancy should be obtained during the stent placement procedure, because it may be helpful in modifying the further management of the stented patient [34-36].

Preparation of obstructed patients with an enema to clean the colon distal to the stenosis is suggested to facilitate the stent placement procedure (weak recommendation, low quality evidence). Antibiotic prophylaxis in obstructed patients undergoing colon stenting is not indicated because the risk of post-procedural infections is very low (strong recommendation, moderate quality evidence).
There are no studies to date that have focused on bowel preparation before stent placement in obstructed patients. Symptomatic bowel obstruction is a relative contraindication to oral bowel cleansing. An enema is advisable to facilitate the stent placement procedure by cleaning the bowel distal to the stenosis.

Antibiotic prophylaxis before stent placement in patients with malignant colonic obstruction is not indicated because the risk of fever and bacteremia after stent insertion is very low. One prospective study analyzed 64 patients with colorectal cancer who underwent a stent procedure. Four of 64 patients (6.3\%) had a positive post-stenting blood culture and none of the patients developed symptoms of infection within 48 hours following stent placement. Prolonged procedure time was associated with transient bacteremia ( 36 vs. 16 minutes, $P<0.01$ ) [37]. One other retrospective series of 233 patients undergoing colonic stent placement for malignant obstruction described that blood cultures had been drawn for unspecified reasons in 30 patients within 2 weeks after stent placement, showing bacteremia/fever in 7 patients (3\%), which was reported as a minor complication [15].

Colonic stent placement should be performed or directly supervised by an experienced operator who has performed at least 20 colonic stent placement procedures (strong recommendation, low quality evidence).

Two noncomparative studies addressed the learning curve of a single endoscopist performing colonic stent placement. Both showed an increase in technical success and a decrease in the number of stents used per procedure after performance of at least 20 procedures $[38,39]$. Two other retrospective series have shown that operator experience affects stenting outcome. The first reported significantly higher technical and clinical success rates when the stent was inserted by an operator who had performed at least 10 SEMS procedures [16]. The second showed a significantly increased immediate perforation rate when colonic stent placement was performed by endoscopists inexperienced 
in pancreaticobiliary endoscopy [15]. The authors of the latter article explained the lower immediate perforation rate by the skills that therapeutic ERCP endoscopists have in traversing complex strictures, understanding fluoroscopy, and deploying stents [15].

\section{Technical considerations of stent placement \\ ( $\odot$ Table e2, available online) \\ $\nabla$}

Colonic stent placement is recommended with the combined use of endoscopy and fluoroscopy (weak recommendation, low quality evidence).

SEMS placement can be performed by using either the throughthe-scope (TTS) or the over-the-guidewire (OTW) technique. The majority of SEMS are inserted through the endoscope with the use of fluoroscopic guidance. The OTW technique is performed using fluoroscopic guidance with or without tandem endoscopic monitoring. Purely radiologic stent placement is performed by advancing the stent deployment system over a stiff guidewire, and technical and clinical success rates of $83 \%-100 \%$ and $77 \%$ $98 \%$, respectively, have been reported in observational studies [40-45]. Retrospective studies that compared endoscopy combined with fluoroscopic guidance versus solely radiography for stent placement show comparable success rates, although with a trend towards higher technical success when the combined technique is used [16, 46-48].

Stricture dilation either before or after stent placement is discouraged in the setting of obstructing colorectal cancer (strong recommendation, low quality evidence).

Although based on low quality evidence with small patient numbers, there are strong indications to believe that stricture dilation either just before or after colonic stent placement adversely affects the clinical outcome of stenting and particularly increases the risk of colonic perforation $[8,12,15,49]$. Pooled analyses, mainly based on retrospective data, also show increased risk of perforation after stricture dilation $[47,50,51]$.

Covered and uncovered SEMS are equally effective and safe (high quality evidence). The stent should have a body diameter $\geq 24 \mathrm{~mm}$ (strong recommendation, low quality evidence) and a length suitable to extend at least $2 \mathrm{~cm}$ on each side of the lesion after stent deployment (weak recommendation, low quality evidence).

The clinician should be aware of specific features of the chosen stent that may affect the patient after insertion. Two meta-analyses comparing covered and uncovered SEMS for malignant colonic obstruction found similar technical success, clinical success, and overall complication rates. Uncovered SEMS showed significantly higher tumor ingrowth rates ( $11.4 \%$ vs. $0.9 \%)$ but were less prone to migrate than covered SEMS (5.5\% vs. $21.3 \%$ ) [52,53].

The diameter of the stent also seems to influence stent outcome. In mainly retrospective analyses, the use of small-diameter stents with a body diameter $<24 \mathrm{~mm}$ was associated with the occurrence of complications, in particular stent migration $[15,54-$ 56]. Stent length was not identified in observational studies as a risk factor for adverse stent outcome $[8,11,16,45]$. It is recommended to use a stent that is long enough to bridge the stenosis and to extend at least $2 \mathrm{~cm}$ on each side of the lesion, taking into account the degree of shortening after stent deployment [57]. Several studies, including one RCT, have shown no difference in outcomes (efficacy and safety) based on different stent designs $[8,43,58-61]$.
Surgical resection is suggested as the preferred treatment for malignant obstruction of the proximal colon in patients with potentially curable disease (weak recommendation, low quality evidence). In a palliative setting, SEMS can be an alternative to emergency surgery (weak recommendation, low quality evidence).

Retrospective series have shown that SEMS may be successfully placed in malignant strictures located in the proximal colon (i.e. proximal to the splenic flexure) $[8,16,62-64]$. However, these data show conflicting results regarding SEMS outcome compared with stent placement in the left-sided colon $[8,11,15,16,45,62$, $65,66]$. Emergency resection is generally considered to be the treatment of choice for right-sided obstructing colon cancer. In this setting, primary ileocolonic anastomosis or ileostomy can be performed depending on the surgical risk of the patient $[5$, $67,68]$.

SEMS placement is a valid alternative to surgery for the palliation of malignant extracolonic obstruction (weak recommendation, low quality evidence). The technical and clinical success rates of stenting for extracolonic malignancies are inferior to those reported in stenting of primary colonic cancer (low quality evidence).

Large-bowel obstruction caused by extracolonic malignancies is a different entity within colonic stenting and has been studied mainly retrospectively. Technical and clinical success rates of stenting extracolonic malignancies have been reported to range from $67 \%$ to $96 \%$ and from $20 \%$ to $96 \%$, respectively [65, 69-75], and are considered inferior to those reported in stenting of primary colonic cancer $[8,55,70,74]$. One retrospective comparison of SEMS for extracolonic versus primary colonic malignancy showed an increased complication rate in the extracolonic malignancy group ( $33 \%$ vs. $9 \%, P=0.046$ ), although this finding was not statistically significant in the multivariate analysis [74]. However, several larger series did not identify obstruction by extrinsic compression as a risk factor for complications $[8,11,15,70]$. It is generally advisable to attempt palliative stenting of extracolonic malignancies in order to avoid surgery in these patients who have a relatively short survival (median survival 30-141 days) $[69,70,72,73]$.

There is insufficient evidence to discourage colonic stenting based on the length of the stenosis (weak recommendation, low quality evidence) or the degree of obstruction (strong recommendation, low quality evidence).

Few studies investigated the "stentability" of long obstructed segments $[58,76,77]$. However, in two retrospective studies that included a total of 240 patients, a better outcome was observed when SEMS were inserted in short obstructed segments [55,78]. One identified statistically significantly more technical failures (odds ratio [OR] 5.33) and clinical failures (OR 2.40) in stenoses $>4 \mathrm{~cm}$ [55].

The outcomes of SEMS placement for complete obstruction compared with subtotal obstruction are reported inconsistently in the literature. One comparative prospective study that specifically focused on this topic found similar technical and clinical success rates between both groups [79]. This was confirmed by more recently published large retrospective series [8, 55]. However, in two observational studies significantly more complications were observed in the complete occlusion group (35\% and $38 \%$ vs. $20 \%$ and $22 \%$ ) $[13,15]$. Furthermore, multivariate analysis in one prospective multicenter study, which reported an $11 \%$ overall perforation rate, identified complete obstruction as a risk factor for perforation (OR 6.88) [80]. 
Clinical indication: SEMS placement as a bridge to elective surgery ( $\bullet$ Table e3, available online) $\nabla$

Colonic SEMS placement as a bridge to elective surgery is not recommended as a standard treatment of symptomatic left-sided malignant colonic obstruction (strong recommendation, high quality evidence). For patients with potentially curable left-sided obstructing colonic cancer, stent placement may be considered as an alternative to emergency surgery in those who have an increased risk of postoperative mortality, i.e. ASA $\geq$ III and/or age $>70$ years (weak recommendation, low quality evidence).

Eight systematic reviews with meta-analysis have been published in the last decade that compared preoperative stenting with emergency resection for acute malignant left-sided colonic obstruction [81-88]. Three of the seven RCTs published to date on this subject $[30,31,89$-93] were prematurely closed, including two because of adverse outcomes in the stent group [30,31] and one because of a high incidence of anastomotic leakage in the primary surgery group [92].

The most recent systematic review and meta-analysis evaluated the efficacy and safety of colonic stenting as a bridge to surgery $(n=195)$ compared with emergency surgery $(n=187)$ and considered only RCTs for inclusion ( Table 7) [81]. All seven RCTs that focused on the postoperative outcome of SEMS and emergency surgery were included in this meta-analysis. The mean technical success rate of colonic stent placement was $76.9 \%$ (range $46.7 \%-100 \%$ ) [81]. There was no statistically significant difference in the postoperative mortality comparing SEMS as bridge to surgery (10.7\%) and emergency surgery (12.4\%) [81]. The meta-analysis showed the SEMS group had lower overall morbidity (33.1\% vs. 53.9\%, $P=0.03$ ), a higher successful primary anastomosis rate $(67.2 \%$ vs. $55.1 \%, P<0.01)$, and lower permanent stoma rate ( $9 \%$ vs. $27.4 \%, P<0.01$ ) [81].

No clear conclusions may be drawn about differences in costs between the two procedures. In the two RCTs that compared costs between SEMS as bridge to surgery and emergency surgery, stenting seems to be the more costly strategy [91, 92]. Cost-effectiveness depends on the rate of stent complications, in particular perforation, and a greater benefit of stenting is expected in high risk surgical patients [94].

From the above data, some advantages of SEMS as a bridge to surgery can be extracted. However, this has to be balanced with the oncological outcomes in patients with a curable colonic cancer. Potential concerns have been raised about impaired oncological outcome after SEMS placement in the patient with potentially curable colon cancer, particularly following stent perforation. Long-term oncological outcome comparing SEMS as a bridge to elective surgery versus acute resection was analyzed by three RCTs ( Table 8 ) $[90,92,95]$. Although the study groups were small, with 15 to 26 patients in the stent arms, all three report higher disease recurrence rates in the SEMS group. This did not translate into a worse overall survival in any of these RCTs, but this may be related to short follow-up and small sample sizes $[90,92,95]$. These results are further supported by a larger comparative prospective cohort study showing significantly more local disease recurrences in the stent group compared with the primary surgery group in patients $\leq 75$ years of age [96]. However, no difference in survival was seen between the two groups. One retrospective analysis reported a significantly lower 5-year overall survival and significantly increased cancer-related mortality in the SEMS as bridge-to-surgery group [97]. The use of SEMS and the occurrence of tumor perforation were identified to corre- late with worse overall survival. Follow-up data of the Stent-in 2 trial also showed a significantly higher overall recurrence rate in the SEMS group compared with the surgery group ( $42 \%$ vs. $25 \%$ ), which was even higher in the subgroup of patients who experienced stent-related perforation (83\%) [95].

The oncological risks of SEMS should be balanced against the operative risks of emergency surgery. Because there is no reduction in postoperative mortality and stenting seems to impact on the oncological safety, the use of SEMS as a bridge to elective surgery is not recommended as a standard treatment for potentially curable patients with left-sided malignant colonic obstruction. However, placement of SEMS may be considered an alternative option in patients at high surgical risk. The known risk factors associated with adverse outcomes following elective as well as emergency surgery in colorectal cancer are increasing age and an ASA score $\geq$ III $[3,17-19,98,99]$. Therefore, the use of SEMS as a bridge to elective surgery may be considered an acceptable alternative treatment option in patients older than 70 years and/or with an ASA score $\geq$ III [100].

A time interval to operation of 5-10 days is suggested when SEMS is used as a bridge to elective surgery in patients with potentially curable left-sided colon cancer (weak recommendation, low quality evidence).

There are limited data to determine an optimal time interval to operation following stent placement as a bridge to surgery. Theoretically, a longer interval ( $>1$ week) will allow for better recovery and more nearly optimal nutritional status, but this may increase the risk of stent-related complications and may compromise surgery by more local tumor infiltration and fibrosis. Therefore we suggest a 5 - to 10-day interval between SEMS and elective resection. Data from the abstract of one RCT $(n=49)$ published in Chinese, which compared laparoscopic resection 3 and 10 days after stent placement, reported a significantly higher primary anastomosis rate and a lower conversion rate to open procedure when surgery was deferred until 10 days after stenting [101]. A retrospective analysis revealed an anastomotic leakage rate of $20 \%$ (3/15) for an interval of 1 to 9 days and $0 \%(0 / 28)$ when surgery was delayed for 10 days or longer $(P=0.037)$ [102]. A published abstract comparing resection within 7 days $(n=26)$ and after 7 days $(n=30)$ of stent placement, found no differences in the postoperative morbidity and mortality [103]. In the literature, a median time interval to surgery of 10 days is a common practice considering the patient's clinical condition, potential risk of stent-related complications, and impact on oncological outcomes [84].

\section{Clinical indication: palliative SEMS placement ( Table e4, available online) $\nabla$}

SEMS placement is the preferred treatment for palliation of malignant colonic obstruction (strong recommendation, high quality evidence).

Two meta-analyses, including randomized and nonrandomized comparative studies, have compared SEMS ( $n=195$ and $n=404)$ and surgery $(n=215$ and $n=433)$ for palliation of malignant colonic obstruction ( Table 9) [104, 105]. The technical success of stent placement in the studies included ranged from $88 \%$ to $100 \%[6,106]$, while the initial clinical relief of obstruction was significantly higher after palliative surgery (100\%) compared with stent placement $(93 \% ; P<0.001)[104,105]$. 
Table 7 Short-term outcomes of self-expandable metal stent (SEMS) placement as a bridge to elective surgery.

\begin{tabular}{|c|c|c|c|}
\hline $\begin{array}{l}\text { First author, } \\
\text { year }\end{array}$ & Study population & Results & $\begin{array}{l}\text { Study design } \\
\text { Level of evidence }\end{array}$ \\
\hline $\begin{array}{l}\text { Huang, } \\
2014 \text { [81] }\end{array}$ & $\begin{array}{l}\text { Patients with acute left-sided } \\
\text { malignant colonic obstruction } \\
7 \text { RCTs } \\
\text { Preoperative SEMS ( } n=195) \\
\text { Emergency surgery }(n=187)\end{array}$ & 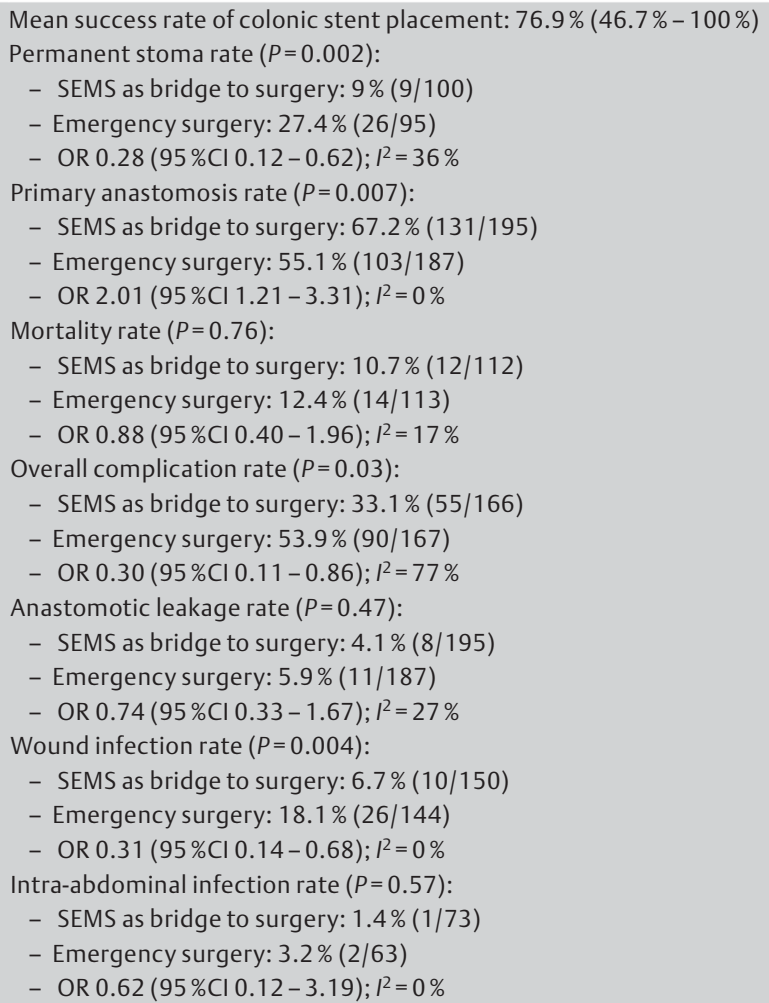 & $\begin{array}{l}\text { Meta-analysis of } \\
\text { RCTs } \\
\text { High quality } \\
\text { evidence }\end{array}$ \\
\hline $\begin{array}{l}\text { Guo, } \\
2011 \text { [100] }\end{array}$ & $\begin{array}{l}\text { Patients aged } \geq 70 \text { years diagnosed } \\
\text { with acute left-sided colonic } \\
\text { obstruction } \\
\text { SEMS }(n=34) \\
\text { Surgery }(n=58)\end{array}$ & $\begin{array}{l}\text { SEMS versus surgery } \\
\text { Overall rate of successful bridging with SEMS: } 79 \% \\
\text { Mean time to elective surgery: } 9 \text { days (range } 4-16) \\
\text { Successful relief of obstruction: } 91 \% \text { vs. } 100 \%(P=0.09) \\
\text { Primary anastomosis rate: } 79 \% \text { vs. } 47 \%(P=0.002) \\
\text { Temporary stoma rate: } 9 \% \text { vs. } 53 \%(P<0.001) \\
\text { Permanent stoma rate: } 6 \% \text { vs. } 12 \%(P=0.34) \\
\text { Median length of hospital stay: } 19 \text { vs. } 14 \text { days ( }(P=0.06) \\
\text { Acute mortality rate: } 3 \% \text { vs. } 19 \%(P=0.03) \\
\text { Acute complication rate: } 24 \% \text { vs. } 40 \%(P=0.11)\end{array}$ & $\begin{array}{l}\text { Retrospective com- } \\
\text { parison } \\
\text { Low quality evidence }\end{array}$ \\
\hline
\end{tabular}

$\mathrm{Cl}$, confidence interval; OR, odds ratio; RCT, randomized controlled trial; SEMS, self-expandable metal stent.

Both meta-analyses showed a lower 30-day mortality rate for SEMS, but it was significant only in the larger meta-analysis ( $4 \%$ vs. $11 \%$, SEMS vs. surgery, respectively) [105]. Placement of a SEMS was significantly associated with a shorter hospitalization (10 vs. 19 days) and a lower intensive care unit (ICU) admission rate $(0.8 \%$ vs. $18.0 \%)$ [104,105], while permitting a shorter time to initiation of chemotherapy (16 vs. 33 days) [105,107]. Surgical stoma formation was significantly lower after palliative SEMS compared with emergency surgery (13\% vs. 54\%) [105].

The larger meta-analysis showed no significant difference in overall morbidity between the stent group (34\%) and the surgery group (38\%) [105]. Short-term complications did occur more often in the palliative surgery group, while late complications were more frequent in the SEMS group. Stent-related complications mainly included colonic perforation (10\%), stent migration (9\%) and re-obstruction (18\%) [105].

The aforementioned results are supported by other recently published literature, including one RCT that was not included in the meta-analyses [11,55,108-114].

There are insufficient data regarding the outcome of stent placement in patients with peritoneal carcinomatosis ( Table e1, available online). One large retrospective study showed a significantly lower technical success rate in patients with carcinomatosis compared with patients without carcinomatosis ( $83 \%$ vs. $93 \%$ ) [8]. Another series, that focused on the outcomes of secondary SEMS insertion after initial stent failure, reported a significantly decreased stent patency in the setting of carcinomatosis (118 days vs. 361 days) [115]. Despite the lower probability of success, SEMS placement may be an alternative to surgical decompression in the setting of peritoneal carcinomatosis. However, there is a lack of evidence to underpin a definite recommendation on this topic.

Patients who have undergone palliative stenting can be safely treated with chemotherapy without antiangiogenic agents (strong recommendation, low quality evidence). Given the high risk of colonic perforation, it is not recommended to use SEMS as palliative decompression if a patient is being treated or considered for treatment with antiangiogenic therapy (e.g. bevacizumab) (strong recommendation, low quality evidence).

It has been speculated that chemotherapy during stenting might induce stent-related complications, in particular perforation. 
Table 8 Oncological outcome of self-expandable metal stent (SEMS) placement.

\begin{tabular}{|c|c|c|c|}
\hline $\begin{array}{l}\text { First author, } \\
\text { year }\end{array}$ & Study population & Results & $\begin{array}{l}\text { Study design } \\
\text { Level of evidence }\end{array}$ \\
\hline $\begin{array}{l}\text { Sloothaak, } \\
2013 \text { [95] }^{1}\end{array}$ & $\begin{array}{l}\text { Patients with acute left-sided colonic } \\
\text { obstruction, proven malignancy, and } \\
\text { curable disease } \\
\text { Preoperative SEMS }(n=26) \\
\text { Emergency surgery }(n=32)\end{array}$ & $\begin{array}{l}\text { Median follow-up: } \\
\text { - SEMS as bridge to surgery: } 36 \text { months (IQR } 34-49) \\
\text { - Emergency surgery: } 38 \text { months (IQR } 18-44) \\
\text { 5-year overall recurrence rate }(P=0.027) \text { : } \\
\text { - SEMS as bridge to surgery: } 42 \%(11 / 26) \\
\text { - Emergency surgery: } 25 \%(8 / 32) \\
\text { Locoregional recurrence rate }(P=0.052) \text { : } \\
\text { - SEMS as bridge to surgery: } 19 \%(5 / 26) \\
\text { - Surgery: } 9 \%(3 / 32) \\
\text { Cumulative incidence of overall recurrences }(P<0.01) \text { : } \\
\text { - Patients with stent-perforation: } 83 \%(95 \% \mathrm{Cl} 58 \%-100 \%) \\
\text { - Non-perforated stent patients: } 34 \%(95 \% \mathrm{Cl} 18 \%-65 \%) \\
\text { - Emergency surgery: } 26 \%(95 \% \mathrm{Cl} 14 \%-47 \%) \\
\text { 5-year cumulative incidence of locoregional recurrences }(P=0.053) \text { : } \\
\text { - Patients with stent perforation: } 50 \%(95 \% \mathrm{Cl} 22 \%-100 \%) \\
\text { - Non-perforated stent patients: } 10 \%(95 \% \mathrm{Cl} 3 \%-28 \%) \\
\text { - Emergency surgery: } 11 \%(95 \% \mathrm{Cl} 3 \%-41 \%)\end{array}$ & $\begin{array}{l}\text { Follow-up data of } \\
\text { RCT [31] } \\
\text { Moderate quality } \\
\text { evidence }\end{array}$ \\
\hline $\begin{array}{l}\text { Tung, } \\
2013 \text { [90] }\end{array}$ & $\begin{array}{l}\text { Patients with obstructing left-sided } \\
\text { colon cancer } \\
\text { Preoperative SEMS }(n=24) \\
\text { Emergency surgery }(n=24)\end{array}$ & $\begin{array}{l}\text { Median follow-up ( } P=0.083) \text { : } \\
\text { - SEMS as bridge to surgery: } 65 \text { months (range } 18-139) \\
\text { - Emergency surgery: } 32 \text { months (range } 4-118) \\
\text { Operation with curative intent }(P=0.01) \text { : } \\
\text { - SEMS as bridge to surgery: } 91 \%(22 / 24) \\
\text { - Emergency surgery: } 54 \%(13 / 24) \\
\text { Lymph node harvest }(P=0.005) \text { : } \\
\text { - SEMS as bridge to surgery: } 23 \text { lymph nodes } \\
\text { - Emergency surgery: } 11 \text { lymph nodes } \\
\text { Overall recurrent disease }(P=0.4): \\
\text { - SEMS as bridge to surgery: } 50 \%(11 / 22) \\
\text { - Emergency surgery: } 23 \%(3 / 13) \\
\text { 5-year overall survival rate }(P=0.076): \\
\text { - SEMS as bridge to surgery: } 48 \% \\
\text { - Emergency surgery: } 27 \% \\
\text { 5-year disease-free survival rate }(P=0.63): \\
\text { - SEMS as bridge to surgery: } 52 \% \\
\text { - Emergency surgery: } 48 \%\end{array}$ & $\begin{array}{l}\text { Follow-up data of } \\
\text { RCT [93] } \\
\text { Moderate quality } \\
\text { evidence }\end{array}$ \\
\hline $\begin{array}{l}\text { Alcantara, } \\
2011 \text { [92] }\end{array}$ & $\begin{array}{l}\text { Patients with complete intestinal } \\
\text { obstruction due to tumor in the left } \\
\text { colon } \\
\text { SEMS as bridge to surgery }(n=15) \\
\text { Intraoperative colonic lavage with } \\
\text { primary anastomosis }(n=13)\end{array}$ & $\begin{array}{l}\text { Overall mean follow-up: } 37.6 \text { months } \\
\text { No difference in overall survival }(P=0.843) \\
\text { Disease-free period }(P=0.096) \text { : } \\
\text { - SEMS as bridge to surgery: } 25.5 \text { months } \\
\text { - Emergency surgery: } 27.1 \text { months } \\
\text { Tumor reappearance }(P=0.055) \text { : } \\
\text { - SEMS as bridge to surgery: } 53 \%(8 / 15) \\
\text { - Emergency surgery: } 15 \%(2 / 13)\end{array}$ & $\begin{array}{l}\text { RCT } \\
\text { Moderate quality } \\
\text { evidence }\end{array}$ \\
\hline $\begin{array}{l}\text { Gorissen, } \\
2013 \text { [96] }\end{array}$ & $\begin{array}{l}\text { Patients with obstructing left-sided } \\
\text { colonic cancer } \\
\text { Preoperative SEMS }(n=62) \\
\text { Emergency surgery }(n=43)\end{array}$ & $\begin{array}{l}\text { Median follow-up ( } P=0.294) \\
\text { - SEMS as bridge to surgery: } 2.7 \text { years } \\
\text { - Emergency surgery: } 2.8 \text { years } \\
\text { Local recurrence rate }(P=0.443) \text { : } \\
\text { - SEMS as bridge to surgery: } 23 \%(14 / 60) \\
\text { - Emergency surgery: } 15 \%(6 / 39) \\
\text { Distant metastasis }(P=1.000) \text { : } \\
\text { - SEMS as bridge to surgery: } 27 \%(16 / 60) \\
\text { - Emergency surgery: } 26 \%(10 / 39) \\
\text { Overall recurrence ( } P=0.824): \\
\text { - SEMS as bridge to surgery: } 32 \%(19 / 60) \\
\text { - Emergency surgery: } 28 \%(11 / 39) \\
\text { Overall mortality }(P=0.215): \\
\text { - SEMS as bridge to surgery: } 29 \%(18 / 62) \\
\text { - Emergency surgery: } 44 \%(19 / 43) \\
\text { Cancer-specific mortality }(P=0.180): \\
\text { - SEMS as bridge to surgery: } 24 \%(15 / 62) \\
\text { - Emergency surgery: } 37 \%(16 / 43) \\
\text { Local recurrence rate in patients } \leq 75 \text { years }(P=0.038) \text { : } \\
\text { - SEMS as bridge to surgery: } 32 \% \\
\text { - Emergency surgery: } 8 \%\end{array}$ & $\begin{array}{l}\text { Prospective cohort } \\
\text { study } \\
\text { Moderate quality } \\
\text { evidence }\end{array}$ \\
\hline
\end{tabular}


Table 8 (Continuation)

\begin{tabular}{|c|c|c|c|}
\hline $\begin{array}{l}\text { First author, } \\
\text { year }\end{array}$ & Study population & Results & $\begin{array}{l}\text { Study design } \\
\text { Level of evidence }\end{array}$ \\
\hline $\begin{array}{l}\text { Sabbagh, } \\
2013 \text { [97] }\end{array}$ & $\begin{array}{l}\text { Patients operated on for left-sided } \\
\text { malignant colonic obstruction with } \\
\text { curative intent } \\
\text { Preoperative SEMS }(n=48) \\
\text { Emergency surgery }(n=39)\end{array}$ & $\begin{array}{l}\text { Mean follow-up ( } P=0.21) \text { : } \\
\text { - SEMS as bridge to surgery: } 28 \text { months } \\
\text { - Emergency surgery: } 32 \text { months } \\
\text { 5-year overall survival rate ( }(P<0.001) \text { : } \\
\text { - SEMS as bridge to surgery: } 25 \% \\
\text { - Emergency surgery: } 62 \% \\
\text { 5-year cancer-specific mortality }(P=0.02) \text { : } \\
\text { - SEMS as bridge to surgery: } 48 \% \\
\text { - Emergency surgery: } 21 \% \\
\text { 5-year disease-free survival }(P=0.24) \text { : } \\
\text { - SEMS as bridge to surgery: } 22 \% \\
\text { - Emergency surgery: } 32 \% \\
\text { Overall recurrence rate }(P=0.18) \text { : } \\
\text { - SEMS as bridge to surgery: } 33 \% \\
\text { - Emergency surgery: } 20 \% \\
\text { Mean time to recurrence }(P=0.92) \text { : } \\
\text { - SEMS as bridge to surgery: } 16 \text { months } \\
\text { - Emergency surgery: } 23 \text { months } \\
\text { In multivariate analysis SEMS (HR } 2.42,95 \% \mathrm{Cl} 1.13-5.18 \text { ) and tumor per- } \\
\text { foration (HR } 5.96,95 \% \mathrm{Cl} 1.70-20.95) \text { were associated with overall survival }\end{array}$ & $\begin{array}{l}\text { Retrospective inten- } \\
\text { tion-to-treat analysis } \\
\text { Low quality evidence }\end{array}$ \\
\hline
\end{tabular}

$\mathrm{Cl}$, confidence interval; $\mathrm{HR}$, hazard ratio; IQR, interquartile range; $\mathrm{RCT}$, randomized controlled trial. 1 Published in abstract form;

Several retrospective series reported an increased risk of stent perforation $(17 \%-50 \%)$ in patients treated with bevacizumab, an angiogenesis inhibitor $[15,55,116]$. A meta-analysis, searching for risk factors of stent perforation in a heterogeneous population, found a significantly increased perforation rate in patients receiving bevacizumab (12.5\%) compared with patients who received no concomitant therapy during colorectal stenting (9.0\%), while chemotherapy without bevacizumab was not associated with an increased risk of stent perforation (7.0\%) [51]. Despite the lack of evidence, an increased perforation risk can reasonably be extrapolated to the newer antiangiogenic agents, aflibercept and regorafenib, because of the similar therapeutic mechanism. Therefore, SEMS placement is strongly discouraged for patients who are being treated or considered for further treatment with antiangiogenic drugs.

Low quality published evidence showed contradictory results regarding the outcome of stenting during chemotherapy $[8,11$, 117]. Nevertheless, no clear increase in adverse events has been observed with colonic stenting. Palliative chemotherapy in patients with a colonic stent is associated with prolonged survival $[76,118]$, and might therefore result in more patients being exposed to the risk of late stent complications. Suspicion of an association between chemotherapy and the occurrence of stent migration due to tumor shrinkage is prompted by several retrospective series $[43,119,120]$.

Long-term stent complications are not automatically an argument in favor of palliative surgery. The lower short-term mortality and the early start of chemotherapy because of SEMS should not be disregarded.

\section{Adverse events related to colonic stenting \\ ( Table e5, available online) \\ $\nabla$}

When stent obstruction or migration occurs in the palliative setting, endoscopic re-intervention by stent-in-stent placement or SEMS replacement is suggested (weak recommendation, low quality evidence). Surgery should always be considered in patients with stentrelated perforation (strong recommendation, low quality evidence). Colonic SEMS placement in patients with malignant large-bowel obstruction is associated with potential adverse events. However, the 30-day stent-related mortality rate is less than $4 \%[11,12$, 105]. Median stent patency in the palliative setting ranges widely between 55 days and 343 days $[58,59]$. One systematic review published in 2007 found a median stent patency of 106 days (range 68-288 days) in the palliative stent population [121]. Around $80 \%$ (range $53 \%-90 \%$ ) of patients maintain stent patency until death or end of follow-up $[48,55,109,113,117,122]$. In the bridge-to-surgery setting, stent patency is maintained until surgery in the large majority of patients.

Adverse events related to colonic stent placement are usually divided into early ( $\leq 30$ days) and late ( $>30$ days). The main early complications are perforation (range $0 \%-12.8 \%$ ), stent failure after technically successful stent deployment (range 0\%-11.7\%), stent migration (range $0 \%-4.9 \%$ ), re-obstruction (range $0 \%$ $4.9 \%$ ), pain (range $0 \%-7.4 \%$ ), and bleeding (range $0 \%-3.7 \%$ ) $[8,12,31,109]$. Late adverse events related to SEMS mainly include re-obstruction (range $4.0 \%-22.9 \%$ ) and stent migration (range $1.0 \%-12.5 \%$ ), and more rarely perforation (range $0 \%$ $4.0 \%)[8,11,105,109,113,117,122]$, although one RCT reported late perforations in 4 out of 10 stent patients [123]. Other SEMS complications reported less frequently in the literature are tenesmus (up to $22 \%$, related to rectal SEMS), incontinence, and fistula $[16,109,112,122]$.

Stent-related perforation may result from different causes which can be classified as proposed by Baron et al.: (i) guidewire or catheter malpositioning; (ii) dilation of the stricture before or after stent placement; (iii) stent-induced perforation (tumor and 
Table9 Meta-analyses of palliative self-expandable metal stent (SEMS) placement.

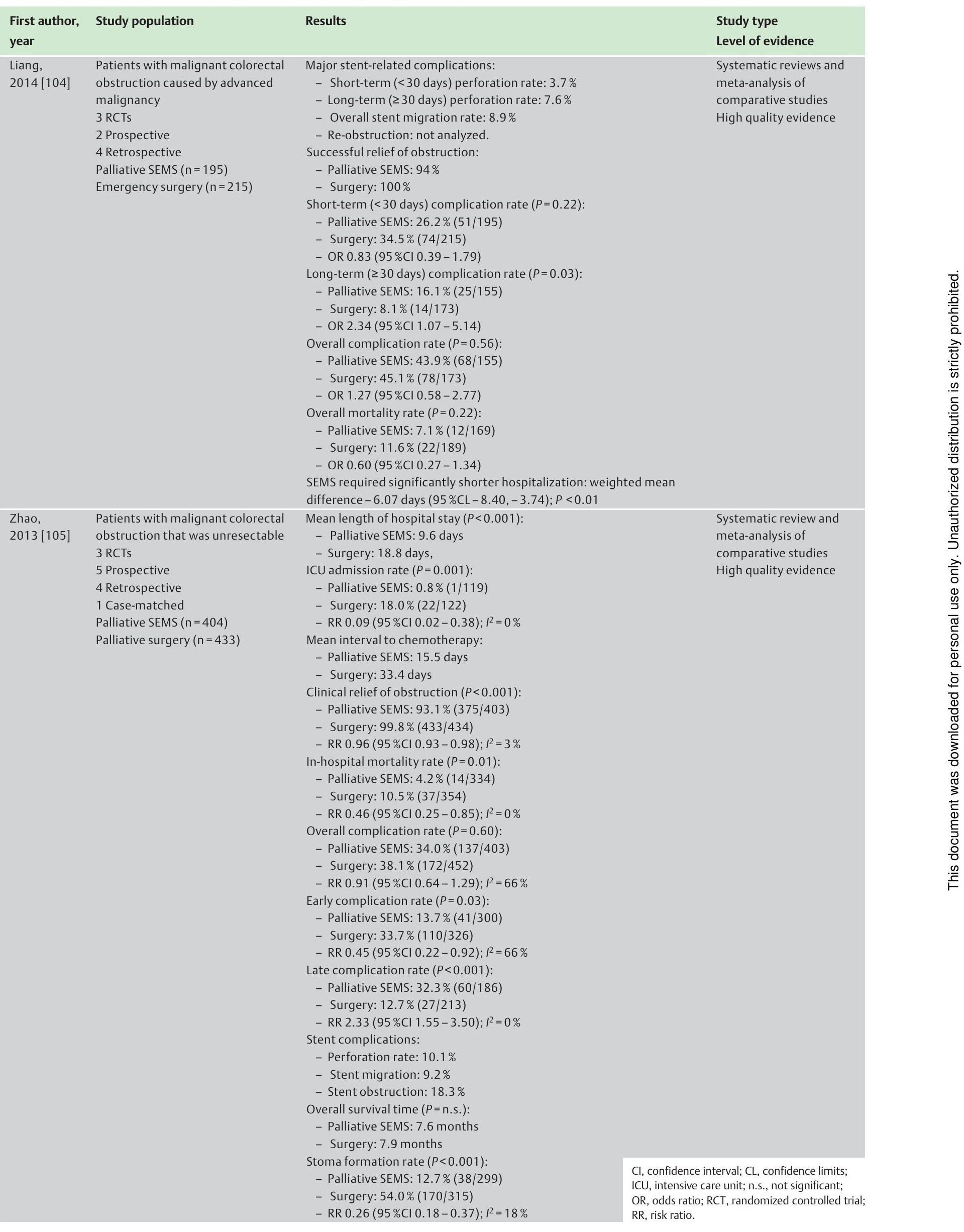


nontumor local perforation); and (iv) proximal colonic distension because of inadequate colonic decompression or excessive air insufflation [57]. The final outcome of stent perforation has been inconsistently reported in the literature, although a perforationrelated mortality rate of $50 \%$ is observed in a number of prospective and retrospective studies $[11,55,120,123]$. Furthermore, there are strong indications that perforation compromises the oncological outcome in patients with colorectal cancer [95,97, 124]. Concurrent bevacizumab therapy, intraprocedural and post-stenting stricture dilation, and diverticular strictures were identified by several studies as risk factors for stent-related perforation $[12,15,33,47,51,55]$.

Stent migration can occur at any time following colonic stenting. Factors that have been identified to correlate with the occurrence of migration are use of covered SEMS and of small-diameter $(<24 \mathrm{~mm})$ stents $[15,52,54,55]$, and there is some evidence that chemotherapy may also be associated with stent migration by the mechanism of tumor shrinkage $[43,119,120]$.

Tumor ingrowth/overgrowth is the main cause of stent re-obstruction and usually occurs during the long-term course of stent therapy. The use of uncovered SEMS is a risk factor for tumor ingrowth [52]. One retrospective series focusing on predictive factors of stent occlusion found that $<70 \%$ stent expansion within the first 48 hours is also predictive for the occurrence of re-obstruction [125].

Both migration and re-obstruction can be managed endoscopically. Stent replacement and stent reopening by a stent-in-stent have been reported as first choice in the majority of papers, with satisfactory results (clinical success $75 \%-86 \%$ ) $[114,115]$, even though the long-term outcome of second stenting or other endoscopic maneuvers is rarely and poorly reported $[11,15,48,76$, $109,110,112]$.

ESGE guidelines represent a consensus of best practice based on the available evidence at the time of preparation. They may not apply in all situations and should be interpreted in the light of specific clinical situations and resource availability. Further controlled clinical studies may be needed to clarify aspects of these statements, and revision may be necessary as new data appear. Clinical consideration may justify a course of action at variance to these recommendations. ESGE guidelines are intended to be an educational device to provide information that may assist endoscopists in providing care to patients. They are not rules and should not be construed as establishing a legal standard of care or as encouraging, advocating, requiring, or discouraging any particular treatment.

Competing interests: J. E. van Hooft: consultancy work for Cook Medical, Boston Scientific, Abbott and Covidien. J. M. Dewitt: consultant for Boston Scientific, Olympus America, and Apollo Endosurgery without grant nor honoria. S. Meisner: consultancy work for Coloplast Denmark, Olympus Denmark, Olympus Europa, Boston Scientific. Dr. V. Muthusami: consultant for Boston Scientific. Dr. A. Repici received a consulting fee and speech fee from Boston Scientific and research grants from Fujifilm, Covidien GI solution and Merit Medical. G. Webster: Advisory Board for Cook Medical and Boston Scientific. All other authors disclosed no financial relationships relevant to this publication.
Institutions

${ }^{1}$ Department of Gastroenterology and Hepatology, Academic Medical Center, Amsterdam, The Netherlands

${ }^{2}$ Centre Hospitalier Universitaire de l'Archet, Pôle digestif, Nice, France

${ }^{3}$ Department of Radiology, Maastricht University Medical Center, The Netherlands

${ }^{4}$ Department of Gastroenterology and Hepatology, Indiana University Medical Center, Indianapolis, Indiana, United States

${ }^{5}$ UBC Division of Gastroenterology, Vancouver General Hospital, Vancouver, Canada

${ }^{6}$ Gedyt Endoscopy Center, Buenos Aires, Argentina

${ }^{7}$ Mount Vernon Cancer Centre, Northwood, Middlesex, UK

${ }^{8}$ Digestive Endoscopy Unit, Catholic University, Rome, Italy

${ }^{9}$ Endoscopy Unit, Gastroenterology Department, Complejo Hospitalario de Navarra, Pamplona, Spain

${ }^{10}$ Endoscopy Unit, Digestive Disease Center, Bispebjerg University Hospital, Copenhagen, Denmark

${ }^{11}$ Division of Gastroenterology and Hepatology, David Geffen School of Medicine at University of California Los Angeles, Los Angeles, California, United States

12 Royal College of Surgeons of England, London, UK

${ }^{13}$ Department of Digestive and Oncological Surgery, University Hospital of Amiens, France

${ }^{14}$ Department of Colorectal Surgery, Royal Surrey County Hospital, Guildford, UK

${ }^{15}$ Department of Surgery, Academic Medical Center, Amsterdam, The Netherlands

${ }^{16}$ Department of Gastroenterology, Onze-Lieve-Vrouwziekenhuis, Aalst, Belgium

${ }^{17}$ Department of Gastroenterology, University College Hospital, London, UK

${ }^{18}$ Department of Gastroenterology and Endoscopy, Guido Salvini Hospital, Garbagnate Milanese/Rho, Milan, Italy

${ }^{19}$ Department of Gastroenterology, Hôpital Nord, Aix Marseille Université, Marseille, France

20 Digestive Endoscopy Unit, Istituto Clinico Humanitas, Milan, Italy

\section{References}

1 Jemal A, Bray F, Center MM et al. Global cancer statistics. CA Cancer J Clin 2011; 61: 69-90

2 Winner M, Mooney SJ, Hershman DL et al. Incidence and predictors of bowel obstruction in elderly patients with stage IV colon cancer: a population-based cohort study. JAMA Surg 2013; 148: 715 - 722

3 Jullumstro E, Wibe A, Lydersen $S$ et al. Colon cancer incidence, presentation, treatment and outcomes over 25 years. Colorectal Dis 2011; 13: $512-518$

4 Cheynel N, Cortet M, Lepage C et al. Trends in frequency and management of obstructing colorectal cancers in a well-defined population. Dis Colon Rectum 2007; 50: 1568-1575

5 Frago R, Ramirez E, Millan M et al. Current management of acute malignant large bowel obstruction: a systematic review. Am J Surg 2014; 207: $127-138$

6 Fiori E, Lamazza A, De Cesare A et al. Palliative management of malignant rectosigmoidal obstruction. Colostomy vs. endoscopic stenting. A randomized prospective trial. Anticancer Res 2004; 24: 265-268

7 Dumonceau JM, Hassan C, Riphaus A et al. European Society of Gastrointestinal Endoscopy (ESGE) Guideline Development Policy. Endoscopy 2012; 44: 626-629

8 Yoon JY, Jung YS, Hong SP et al. Clinical outcomes and risk factors for technical and clinical failures of self-expandable metal stent insertion for malignant colorectal obstruction. Gastrointest Endosc 2011; 74: $858-868$

$9 \mathrm{Kim}$ JH, Ku YS, Jeon TJ et al. The efficacy of self-expanding metal stents for malignant colorectal obstruction by noncolonic malignancy with peritoneal carcinomatosis. Dis Colon Rectum 2013; 56: 1228-1232

10 Song HY, Kim JH, Kim KR et al. Malignant rectal obstruction within 5 $\mathrm{cm}$ of the anal verge: is there a role for expandable metallic stent placement? Gastrointest Endosc 2008; 68: 713-720

11 Abbott S, Eglinton TW, Ma Y et al. Predictors of outcome in palliative colonic stent placement for malignant obstruction. Br J Surg 2014; 101: $121-126$

12 Meisner S, Gonzalez-Huix F, Vandervoort JG et al. Self-expandable metal stents for relieving malignant colorectal obstruction: short-term safety and efficacy within 30 days of stent procedure in 447 patients. Gastrointest Endosc 2011; 74: 876-884

13 Choi JH, Lee YJ, Kim ES et al. Covered self-expandable metal stents are more associated with complications in the management of malignant colorectal obstruction. Surg Endosc 2013; 27: 3220-3227 
14 Donnellan F, Cullen G, Cagney D et al. Efficacy and safety of colonic stenting for malignant disease in the elderly. Int J Colorectal Dis 2010; 25: 747-750

15 Small AJ, Coelho-Prabhu N, Baron TH. Endoscopic placement of self-expandable metal stents for malignant colonic obstruction: long-term outcomes and complication factors. Gastrointest Endosc 2010; 71: $560-572$

16 Geraghty J, Sarkar S, Cox T et al. Management of large bowel obstruction with self-expanding metal stents. A multicentre retrospective study of factors determining outcome. Colorectal Dis 2014; 16 : 476- 483

17 Biondo S, Pares D, Frago $R$ et al. Large bowel obstruction: predictive factors for postoperative mortality. Dis Colon Rectum 2004; 47: $1889-1897$

18 Tekkis PP, Kinsman R, Thompson MR et al. The Association of Coloproctology of Great Britain and Ireland study of large bowel obstruction caused by colorectal cancer. Ann Surg 2004; 240: 76-81

19 Tan KK, Sim R. Surgery for obstructed colorectal malignancy in an Asian population: predictors of morbidity and comparison between left- and right-sided cancers. J Gastrointest Surg 2010; 14: 295-302

20 Frager D, Rovno HD, Baer JW et al. Prospective evaluation of colonic obstruction with computed tomography. Abdom Imaging 1998; 23: $141-146$

21 Kodeda K, Nathanaelsson L, Jung B et al. Population-based data from the Swedish Colon Cancer Registry. Br J Surg 2013; 100: 1100-1107

22 Mulder SA, Kranse R, Damhuis RA et al. Prevalence and prognosis of synchronous colorectal cancer: a Dutch population-based study. Cancer Epidemiol 2011; 35: 442 - 447

23 Latournerie M, Jooste $V$, Cottet $V$ et al. Epidemiology and prognosis of synchronous colorectal cancers. Br J Surg 2008; 95: 1528-1533

24 Papadopoulos V, Michalopoulos A, Basdanis $G$ et al. Synchronous and metachronous colorectal carcinoma. Tech Coloproctol 2004; 8: $0197-s 100$

25 Park SH, Lee JH, Lee SS et al. CT colonography for detection and characterisation of synchronous proximal colonic lesions in patients with stenosing colorectal cancer. Gut 2012; 61: 1716-1722

26 Cha EY, Park SH, Lee SS et al. CT colonography after metallic stent placement for acute malignant colonic obstruction. Radiology 2010; 254: $774-782$

27 Lim SG, Lee KJ, Suh KW et al. Preoperative colonoscopy for detection of synchronous neoplasms after insertion of self-expandable metal stents in occlusive colorectal cancer: comparison of covered and uncovered stents. Gut Liver 2013; 7: 311-316

28 Vitale MA, Villotti G, d'Alba L et al. Preoperative colonoscopy after selfexpandable metallic stent placement in patients with acute neoplastic colon obstruction. Gastrointest Endosc 2006; 63: 814-819

29 Nagata $K$, Ota Y, Okawa T et al. PET/CT colonography for the preoperative evaluation of the colon proximal to the obstructive colorectal cancer. Dis Colon Rectum 2008; 51: $882-890$

30 Pirlet IA, Slim K, Kwiatkowski F et al. Emergency preoperative stenting versus surgery for acute left-sided malignant colonic obstruction: a multicenter randomized controlled trial. Surg Endosc 2011; 25: $1814-1821$

31 van Hooft JE, Bemelman WA, Oldenburg B et al. Colonic stenting versus emergency surgery for acute left-sided malignant colonic obstruction: a multicentre randomised trial. Lancet Oncol 2011; 12: 344352

32 Sai VF, Velayos F, Neuhaus J et al. Colonoscopy after CT diagnosis of diverticulitis to exclude colon cancer: a systematic literature review. Radiology 2012; 263: 383-390

33 Currie A, Christmas C, Aldean $H$ et al. Systematic review of self-expanding stents in the management of benign colorectal obstruction. Colorectal Dis 2014; 16: 239-245

34 Brouwer R, MacDonald A, Matthews R et al. Brush cytology for the diagnosis of colorectal cancer. Dis Colon Rectum 2009; 52: 598-601

35 Geramizadeh B, Hooshmand F, Kumar PV. Brush cytology of colorectal malignancies. Acta Cytol 2003; 47: 431 - 444

36 Farouk R, Edwards J, Thorne $M$ et al. Brush cytology for the diagnosis of rectal carcinoma. Br J Surg 1996; 83: 1456-1458

37 Chun YJ, Yoon NR, Park JM et al. Prospective assessment of risk of bacteremia following colorectal stent placement. Dig Dis Sci 2012; 57: $1045-1049$

38 Williams D, Law R, Pullyblank AM. Colorectal stenting in malignant large bowel obstruction: the learning curve. Int J Surg Oncol 2011: DOI 10.1155/2011/917848 doi:
39 Lee JH, Yoon JY, Park SJ et al. The learning curve for colorectal stent insertion for the treatment of malignant colorectal obstruction. Gut Liver 2012; 6: 328-333

$40 \mathrm{Kim}$ SY, Kwon SH, Oh JH. Radiologic placement of uncovered stents for the treatment of malignant colorectal obstruction. J Vasc Interv Radiol 2010; 21: $1244-1249$

$41 \mathrm{Kim} \mathrm{H}$, Kim SH, Choi SY et al. Fluoroscopically guided placement of self-expandable metallic stents and stent-grafts in the treatment of acute malignant colorectal obstruction. J Vasc Interv Radiol 2008; 19: $1709-1716$

42 Shrivastava $V$, Tariq 0 , Tiam $R$ et al. Palliation of obstructing malignant colonic lesions using self-expanding metal stents: a single-center experience. Cardiovasc Intervent Radiol 2008; 31: 931 -936

$43 \mathrm{Kim}$ JH, Song HY, Li YD et al. Dual-design expandable colorectal stent for malignant colorectal obstruction: comparison of flared ends and bent ends. AJR Am J Roentgenol 2009; 193: 248-254

44 Alcantara M, Serra X, Bombardo J et al. Colorectal stenting as an effective therapy for preoperative and palliative treatment of large bowel obstruction: 9 years' experience. Tech Coloproctol 2007; 11: 316 322

45 Selinger CP, Ramesh J, Martin DF. Long-term success of colonic stent insertion is influenced by indication but not by length of stent or site of obstruction. Int J Colorectal Dis 2011; 26: 215-218

$46 \mathrm{Kim} J W$, Jeong JB, Lee KL et al. Comparison of clinical outcomes between endoscopic and radiologic placement of self-expandable metal stent in patients with malignant colorectal obstruction. Korean J Gastroenterol 2013; 61: 22-29

47 Sebastian S, Johnston S, Geoghegan T et al. Pooled analysis of the efficacy and safety of self-expanding metal stenting in malignant colorectal obstruction. Am J Gastroenterol 2004; 99: 2051 - 2057

48 de Gregorio MA, Laborda A, Tejero E et al. Ten-year retrospective study of treatment of malignant colonic obstructions with self-expandable stents. J Vasc Interv Radiol 2011; 22: 870-878

49 Tanaka A, Sadahiro S, Yasuda $M$ et al. Endoscopic balloon dilation for obstructive colorectal cancer: a basic study on morphologic and pathologic features associated with perforation. Gastrointest Endosc 2010; 71: 799-805

50 Khot UP, Lang AW, Murali K et al. Systematic review of the efficacy and safety of colorectal stents. Br J Surg 2002; 89: 1096 - 1102

51 van Halsema EE, van Hooft JE, Small AJ et al. Perforation in colorectal stenting: a meta-analysis and a search for risk factors. Gastrointest Endosc 2014; 79: 970-982 e7

52 Zhang Y, Shi J, Shi B et al. Comparison of efficacy between uncovered and covered self-expanding metallic stents in malignant large bowel obstruction: a systematic review and meta-analysis. Colorectal Dis 2012; 14: e367-374

53 Yang $Z, W u Q$ Wang $F$ et al. A systematic review and meta-analysis of randomized trials and prospective studies comparing covered and bare self-expandable metal stents for the treatment of malignant obstruction in the digestive tract. Int J Med Sci 2013; 10: 825-835

$54 \mathrm{Kim}$ BC, Han KS, Hong CW et al. Clinical outcomes of palliative self-expanding metallic stents in patients with malignant colorectal obstruction. J Dig Dis 2012; 13: 258-266

55 Manes G, de Bellis M, Fuccio $L$ et al. Endoscopic palliation in patients with incurable malignant colorectal obstruction by means of self-expanding metal stent: analysis of results and predictors of outcomes in a large multicenter series. Arch Surg 2011; 146: 1157-1162

56 Im JP, Kim SG, Kang HW et al. Clinical outcomes and patency of selfexpanding metal stents in patients with malignant colorectal obstruction: a prospective single center study. Int J Colorectal Dis 2008; 23: 789-794

57 Baron TH, Wong KeeSong LM, Repici A. Role of self-expandable stents for patients with colon cancer (with videos). Gastrointest Endosc 2012; 75: 653-662

58 Cheung DY, Kim JY, Hong SP et al. Outcome and safety of self-expandable metallic stents for malignant colon obstruction: a Korean multicenter randomized prospective study. Surg Endosc 2012; 26: $3106-$ 3113

59 Park JK, Lee MS, Ko BM et al. Outcome of palliative self-expanding metal stent placement in malignant colorectal obstruction according to stent type and manufacturer. Surg Endosc 2011; 25: 1293-1299

60 Small AJ, Baron TH. Comparison of Wallstent and Ultraflex stents for palliation of malignant left-sided colon obstruction: a retrospective, case-matched analysis. Gastrointest Endosc 2008; 67: 478 - 488 
61 Garcia-Cano J, Gonzalez-Huix F, Juzgado D et al. Use of self-expanding metal stents to treat malignant colorectal obstruction in general endoscopic practice (with videos). Gastrointest Endosc 2006; 64: $914-920$

62 Cho YK, Kim SW, Lee BI et al. Clinical outcome of self-expandable metal stent placement in the management of malignant proximal colon obstruction. Gut Liver 2011; 5: 165 - 710

63 Yao LQ Zhong YS, Xu MD et al. Self-expanding metallic stents drainage for acute proximal colon obstruction. World J Gastroenterol 2011; 17: $3342-3346$

64 Repici A, Adler DG, Gibbs CM et al. Stenting of the proximal colon in patients with malignant large bowel obstruction: techniques and outcomes. Gastrointest Endosc 2007; 66: 940 - 944

$65 \mathrm{Kim}$ JY, Kim SG, Im JP et al. Comparison of treatment outcomes of endoscopic stenting for colonic and extracolonic malignant obstruction. Surg Endosc 2013; 27: 272 - 277

66 Dronamraju SS, Ramamurthy S, Kelly SB et al. Role of self-expanding metallic stents in the management of malignant obstruction of the proximal colon. Dis Colon Rectum 2009; 52: 1657-1661

67 Gainant A. Emergency management of acute colonic cancer obstruction. J Visc Surg 2012; 149: e3 - e10

68 Cuffy M, Abir F, Audisio RA et al. Colorectal cancer presenting as surgical emergencies. Surg Oncol 2004; 13: 149-157

69 Moon SJ, Kim SW, Lee BI et al. Palliative stent for malignant colonic obstruction by extracolonic malignancy: a comparison with colorectal cancer. Dig Dis Sci 29. 09 2013: [Epub ahead of print]

70 Keranen I, Lepisto A, Udd M et al. Stenting for malignant colorectal obstruction: a single-center experience with 101 patients. Surg Endosc 2012; 26: $423-430$

$71 \mathrm{Kim}$ BK, Hong SP, Heo HM et al. Endoscopic stenting is not as effective for palliation of colorectal obstruction in patients with advanced gastric cancer as emergency surgery. Gastrointest Endosc 2012; 75: 294-301

$72 \mathrm{Kim} J \mathrm{H}$, Song HY, Park JH et al. Metallic stent placement in the palliative treatment of malignant colonic obstructions: primary colonic versus extracolonic malignancies. J Vasc Interv Radiol 2011; 22: $1727-1732$

73 Trompetas V, Saunders M, Gossage J et al. Shortcomings in colonic stenting to palliate large bowel obstruction from extracolonic malignancies. Int J Colorectal Dis 2010; 25: 851 - 854

74 Keswani RN, Azar RR, Edmundowicz SA et al. Stenting for malignant colonic obstruction: a comparison of efficacy and complications in colonic versus extracolonic malignancy. Gastrointest Endosc 2009; 69: $675-680$

75 Shin SJ, Kim TI, Kim BC et al. Clinical application of self-expandable metallic stent for treatment of colorectal obstruction caused by extrinsic invasive tumors. Dis Colon Rectum 2008; 51: 578- 583

76 Luigiano C, Ferrara F, Fabbri C et al. Through-the-scope large diameter self-expanding metal stent placement as a safe and effective technique for palliation of malignant colorectal obstruction: a single center experience with a long-term follow-up. Scand J Gastroenterol 2011: 46: 591 - 596

77 Almadi MA, Azzam N, Alharbi $O$ et al. Complications and survival in patients undergoing colonic stenting for malignant obstruction. World J Gastroenterol 2013; 19: 7138-7145

78 Jung MK, Park SY, Jeon SW et al. Factors associated with the long-term outcome of a self-expandable colon stent used for palliation of malignant colorectal obstruction. Surg Endosc 2010; 24: 525-530

79 Stenhouse A, Page B, Rowan A et al. Self expanding wall stents in malignant colorectal cancer: is complete obstruction a contraindication to stent placement? Colorectal Dis 2009; 11: 854-858

80 Song HY, Kim JH, Shin JH et al. A dual-design expandable colorectal stent for malignant colorectal obstruction: results of a multicenter study. Endoscopy 2007; 39: 448-44

81 Huang $X, L v B$, Zhang $S$ et al. Preoperative colonic stents versus emergency surgery for acute left-sided malignant colonic obstruction: a meta-analysis. J Gastrointest Surg 2014; 18: 584-591

82 Cennamo V, Luigiano C, Coccolini F et al. Meta-analysis of randomized trials comparing endoscopic stenting and surgical decompression for colorectal cancer obstruction. Int J Colorectal Dis 2013; 28: 855-863

83 Cirocchi $R$, Farinella E, Trastulli $S$ et al. Safety and efficacy of endoscopic colonic stenting as a bridge to surgery in the management of intestinal obstruction due to left colon and rectal cancer: a systematic review and meta-analysis. Surg Oncol 2013; 22: 14-21
84 De Ceglie A, Filiberti R, Baron TH et al. A meta-analysis of endoscopic stenting as bridge to surgery versus emergency surgery for left-sided colorectal cancer obstruction. Crit Rev Oncol Hematol 2013; 88: $387-403$

85 Tan CJ, Dasari BV, Gardiner K. Systematic review and meta-analysis of randomized clinical trials of self-expanding metallic stents as a bridge to surgery versus emergency surgery for malignant left-sided large bowel obstruction. Br J Surg 2012; 99: 469-476

86 Ye GY, Cui Z, Chen $L$ et al. Colonic stenting vs emergent surgery for acute left-sided malignant colonic obstruction: a systematic review and meta-analysis. World J Gastroenterol 2012; 18: 5608-5615

87 Zhang Y, Shi J, Shi B et al. Self-expanding metallic stent as a bridge to surgery versus emergency surgery for obstructive colorectal cancer: a meta-analysis. Surg Endosc 2012; 26: 110-119

88 Sagar J. Colorectal stents for the management of malignant colonic obstructions. Cochrane Database Syst Rev 2011: CD007378

89 Ghazal AH, El-Shazly WG, Bessa SS et al. Colonic endolumenal stenting devices and elective surgery versus emergency subtotal/total colectomy in the management of malignant obstructed left colon carcinoma. J Gastrointest Surg 2013; 17: 1123-1129

90 Tung KL, Cheung HY, Ng LW et al. Endo-laparoscopic approach versus conventional open surgery in the treatment of obstructing left-sided colon cancer: long-term follow-up of a randomized trial. Asian J Endosc Surg 2013; 6: 78-81

91 Ho KS, Quah HM, Lim JF et al. Endoscopic stenting and elective surgery versus emergency surgery for left-sided malignant colonic obstruction: a prospective randomized trial. Int J Colorectal Dis 2012; 27: $355-362$

92 Alcantara M, Serra-Aracil X, Falco J et al. Prospective, controlled, randomized study of intraoperative colonic lavage versus stent placement in obstructive left-sided colonic cancer. World J Surg 2011; 35: $1904-1910$

93 Cheung HY, Chung CC, Tsang WW et al. Endolaparoscopic approach vs conventional open surgery in the treatment of obstructing left-sided colon cancer: a randomized controlled trial. Arch Surg 2009; 144: $1127-1132$

94 Govindarajan A, Naimark D, Coburn NG et al. Use of colonic stents in emergent malignant left colonic obstruction: a Markov chain Monte Carlo decision analysis. Dis Colon Rectum 2007; 50: 1811-1124

95 Sloothaak D, van den Berg $M$, Dijkgraaf $M$ et al. Recurrences after endoscopic stenting as treatment for acute malignant colonic obstruction in the Dutch Stent-In 2 trial. Conference: 21st UEG Week, October 12-16 Berlin: 2013

96 Gorissen KJ, Tuynman JB, Fryer $E$ et al. Local recurrence after stenting for obstructing left-sided colonic cancer. Br J Surg 2013; 100: 1805 1809

97 Sabbagh C, Browet F, Diouf M et al. Is stenting as "a bridge to surgery" an oncologically safe strategy for the management of acute, left-sided, malignant, colonic obstruction? A comparative study with a propensity score analysis Ann Surg 2013; 258: 107-115

98 Iversen $\mathrm{LH}$. Aspects of survival from colorectal cancer in Denmark. Dan Med J 2012; 59: B4428

99 Symeonidis D, Christodoulidis G, Koukoulis G et al. Colorectal cancer surgery in the elderly: limitations and drawbacks. Tech Coloproctol 2011; 15: 47-50

100 Guo MG, Feng Y, Zheng $Q$ et al. Comparison of self-expanding metal stents and urgent surgery for left-sided malignant colonic obstruction in elderly patients. Dig Dis Sci 2011; 56: 2706-2710

101 Cui J, Zhang JL, Wang $S$ et al. [A preliminary study of stenting followed by laparoscopic surgery for obstructing left-sided colon cancer]. [In Chinese]. Zhonghua Wei Chang Wai Ke Za Zhi 2011; 14: 40-43

102 Lee GJ, Kim HJ, Baek JH et al. Comparison of short-term outcomes after elective surgery following endoscopic stent insertion and emergency surgery for obstructive colorectal cancer. Int I Surg 2013; 11: 442 446

103 Kim S, Park Y, Lee K et al. Optimal time of surgery after preoperative self-expandable metalic stent insertion for obstructive colorectal cancer. Dis Colon Rectum 2009; 52: 853

104 Liang TW, Sun Y, Wei YC et al. Palliative treatment of malignant colorectal obstruction caused by advanced malignancy: a self-expanding metallic stent or surgery? A system review and meta-analysis Surg Today 2014; 44: 22 - 33

105 Zhao XD, Cai BB, Cao RS et al. Palliative treatment for incurable malignant colorectal obstructions: a meta-analysis. World J Gastroenterol 2013; 19: $5565-5574$ 
106 Carne PW, Frye JN, Robertson GM et al. Stents or open operation for palliation of colorectal cancer: a retrospective, cohort study of perioperative outcome and long-term survival. Dis Colon Rectum 2004; 47: $1455-1461$

107 Karoui M, Charachon A, Delbaldo C et al. Stents for palliation of obstructive metastatic colon cancer: impact on management and chemotherapy administration. Arch Surg 2007; 142: 619-623; discussion 623

108 Fiori E, Lamazza A, Schillaci A et al. Palliative management for patients with subacute obstruction and stage IV unresectable rectosigmoid cancer: colostomy versus endoscopic stenting: final results of a prospective randomized trial. Am J Surg 2012; 204: 321 - 326

109 Gianotti L, Tamini N, Nespoli L et al. A prospective evaluation of shortterm and long-term results from colonic stenting for palliation or as a bridge to elective operation versus immediate surgery for large-bowel obstruction. Surg Endosc 2013; 27: 832-842

110 Yoshida $S$, Watabe $H$, Isayama $H$ et al. Feasibility of a new self-expandable metallic stent for patients with malignant colorectal obstruction. Dig Endosc 2013; 25: 160-166

111 Huhtinen $H$, Varpe P, Karvonen J et al. Late complications related to palliative stenting in patients with obstructing colorectal cancer. Minim Invasive Ther Allied Technol 2013; 22: 352 - 358

112 Angenete E, Asplund D, Bergstrom $M$ et al. Stenting for colorectal cancer obstruction compared to surgery - a study of consecutive patients in a single institution. Int J Colorectal Dis 2012; 27: 665-670

113 Meisner S, Gonzalez-Huix F, Vandervoort JG et al. Self-expanding metal stenting for palliation of patients with malignant colonic obstruction: effectiveness and efficacy on 255 patients with 12-month's followup. Gastroenterol Res Pract 2012; 2012: 296347 doi: DOI 10.1155/ 2012/296347 [Epub 2012 Jun 11]

114 Yoon JY, Park SJ, Hong SP et al. Outcomes of secondary self-expandable metal stents versus surgery after delayed initial palliative stent failure in malignant colorectal obstruction. Digestion 2013; 88: 46- 55

115 Yoon JY, Jung YS, Hong SP et al. Outcomes of secondary stent-in-stent self-expandable metal stent insertion for malignant colorectal obstruction. Gastrointest Endosc 2011; 74: 625-633

116 Cennamo V, Fuccio L, Mutri V et al. Does stent placement for advanced colon cancer increase the risk of perforation during bevacizumabbased therapy? Clin Gastroenterol Hepatol 2009; 7: 1174-1176

117 Di Mitri R, Mocciaro F, Traina M et al. Self-expandable metal stents for malignant colonic obstruction: Data from a retrospective regional SIED-AIGO study. Dig Liver Dis 2014; 46: 279-282
118 Lee HJ, Hong SP, Cheon JH et al. Long-term outcome of palliative therapy for malignant colorectal obstruction in patients with unresectable metastatic colorectal cancers: endoscopic stenting versus surgery. Gastrointest Endosc 2011; 73: 535-542

119 Canena JM, Liberato M, Marques I et al. Sustained relief of obstructive symptoms for the remaining life of patients following placement of an expandable metal stent for malignant colorectal obstruction. Rev Esp Enferm Dig 2012; 104: 418-425

120 Fernandez-Esparrach G, Bordas JM, Giraldez MD et al. Severe complications limit long-term clinical success of self-expanding metal stents in patients with obstructive colorectal cancer. Am J Gastroenterol 2010; 105: 1087-1093

121 Watt AM, Faragher IG, Griffin TT et al. Self-expanding metallic stents for relieving malignant colorectal obstruction: a systematic review. Ann Surg 2007; 246: $24-30$

122 Young CJ, Suen MK, Young J et al. Stenting large bowel obstruction avoids a stoma: consecutive series of 100 patients. Colorectal Dis 2011; 13: $1138-1141$

123 van Hooft JE, Fockens P, Marinelli AW et al. Early closure of a multicenter randomized clinical trial of endoscopic stenting versus surgery for stage IV left-sided colorectal cancer. Endoscopy 2008; 40: 184-191

$124 \mathrm{Ho} \mathrm{YH}$, Siu SK, Buttner P et al. The effect of obstruction and perforation on colorectal cancer disease-free survival. World J Surg 2010; 34: $1091-1101$

125 Suh JP, Kim SW, Cho YK et al. Effectiveness of stent placement for palliative treatment in malignant colorectal obstruction and predictive factors for stent occlusion. Surg Endosc 2010; 24: 400-406

126 Cennamo $V$, Luigiano C, Manes $G$ et al. Colorectal stenting as a bridge to surgery reduces morbidity and mortality in left-sided malignant obstruction: a predictive risk score-based comparative study. Dig Liver Dis 2012; 44: 508 - 514

127 Jimenez-Perez J, Casellas J, Garcia-Cano J et al. Colonic stenting as a bridge to surgery in malignant large-bowel obstruction: a report from two large multinational registries. Am J Gastroenterol 2011; 106: $2174-2180$

128 Xinopoulos D, Dimitroulopoulos D, Theodosopoulos $T$ et al. Stenting or stoma creation for patients with inoperable malignant colonic obstructions? Results of a study and cost-effectiveness analysis Surg Endosc 2004; 18: $421-426$

\section{Appendix e1 and e2}

online content viewable at: www.thieme-connect.de 